Wolfgang Hamedinger*

\title{
Austrian Library Network and Next Generation Library System: Alma
}

DOI 10.1515/bfp-2016-0055

\begin{abstract}
After a short description of the historic development of the Austrian Library Network, the article describes the nature of the Library Network's internal cooperation and its homogenous network architecture. The formal selection process and the tendering procedure on the way to Alma are described, with a focus on safeguarding data protection and parallel operation. Relevant results of the process will be displayed and added by consequences to be expected from the new system.
\end{abstract}

Keywords: Austrian Library Network; Ex Libris; Alma; next-generation library system; tendering procedure; cloud-based library solutions

\section{Der Österreichische Bibliotheksverbund und ein Bibliothekssystem der nächsten Generation: Alma}

Zusammenfassung: Der Artikel beschreibt, beginnend mit der historischen Entwicklung des Österreichischen Bibliotheksverbunds, die Kultur seiner internen Zusammenarbeit und seine sehr homogene Verbundarchitektur. Auf dieser Grundlage wird der formale Auswahlprozess für die Systemnachfolge dargestellt, wobei die Bemühungen zur Gewährleistung von Datenschutz und Parallelbetrieb besonders beleuchtet werden. Wesentliche Ergebnisse des Verfahrens werden dargestellt und durch zu erwartende Auswirkungen des neuen Systems ergänzt.

Schlüsselwörter: Österreichischer Bibliotheksverbund; Ex Libris; Alma; Bibliothekssystem der nächsten Generation; Öffentliches Vergabeverfahren; cloud-basiertes Bibliothekssystem

\section{Introduction}

Following a very complex and formal tendering procedure with the purpose to find a solution for an integrated library system to succeed the current systems in place (Aleph 500 and Alephino), the Head Office (OBVSG) plus a core group

*Kontaktperson: Wolfgang Hamedinger, wolfgang.hamedinger@obvsg.at of libraries of the Austrian Library Network (OBV) accepted Ex Libris' bid with ALMA on September 15 ${ }^{\text {th }}, 2015$.

\section{About the Austrian Library Network}

\subsection{History and Organisation}

In order to be able to understand the processes, approaches and decisions following in this paper, a fundamental overview of the development of the Austrian Library Network, its framework conditions and its way of cooperating that developed over the years is both appropriate and essential.

The Austrian Library Network is the large network of academic and research libraries in Austria which by now comprises 73 members being represented in the general assembly. These 73 members represent 94 independent institutions. The Austrian Library Network does not have a formal founding date, however, nationwide cooperation already started in the 1980's and the first fundamental concepts and organisational structures were drawn up even earlier in the 1970's. Based on these first steps, a cooperative system to catalogue periodicals - the Austrian Periodicals Database (ÖZDB) - was set up in 1984 following the role model of and in cooperation with the Periodicals Database in Berlin. In 1987 BIBOS was introduced as the general system to handle monographs. At this time most university libraries and the Austrian National Library were members of the Austrian Library Network.

It is important to note that in the very early and crucial days of the Austrian Library Network all academic federal libraries were under the authority of one single department in the ministry which on the one hand had the authority to issue directives and on the other hand was in charge of resource and budget allocation. This in particular applied to university libraries which were not supervised by university rectorates.

Cooperation among the various members was intensified already during this first stage of the network, as they collaboratively used one library system. Initial fears and concerns were overcome quickly by mutual contact and 
the era of collective and mutual commitment and problemsolving began.

BIBOS showed considerable shortcomings in terms of functionality. As this situation was unsatisfying, a call for tenders covering the complete library system was issued in 1997 following appropriate preparatory steps. Ex Libris won this call for tenders with its integrated library system Aleph 500. Back then, the competent ministry was in charge of decision-making and basic funding, whereas technical and functional experts of the Library Network members prepared and had a crucial influence on the decision which system to choose. This turned out to be the right strategy, as by involving all parties concerned, everybody had a clear understanding of the potentials and (initial) deficiencies of the new system and needless disputes were averted.

In the following years all legacy systems were superseded by Aleph 500 and this new architecture has since then been the basis of synergistic cooperation and integrated services in the Austrian Library Network. The welloiled infrastructure made it possible to accept new members. Over the years the number of members of the Austrian Library Network nearly tripled.

Using the same system for both central and local purposes led to a common language and very similar interests among the different members of the Austrian Library Network which was decisive for the developing additional benefit in terms of organisation. Hence, resources can be bundled, joint approaches can be taken and targets, which are out of reach if pursued alone, can be achieved as a community.

This close cooperation was not impaired by organisational changes in the subsequent years, but was even prolonged when the direct authority of the ministry largely ended. At the beginning of 2002 the Head Office was institutionalised and became autonomous as „Die Österreichische Bibliothekenverbund und Service Ges.m.b.H.“ (OBVSG) including a specified scope of duties and responsibilities laid down in a federal law. The Head Office is solely owned by the state, it is independent from the members and it constitutes the organisational and operative anchor of the Austrian Library Network. At the same time the Austrian National Library became an independent institution. The Universities Act which entailed large-scale autonomy for the universities and which led to the complete integration of the university libraries into the universities was passed in 2002 as well.

Due to the fact that the members of the Austrian Library Network developed into independent institutions without a superordinate planning and controlling body, such as a ministry, and without obligation to participate in the Library Network it became necessary to find a proper set of rules and regulations for the cooperation within the Network. The Head Office and the members organised themselves through a binding "network status", with the Head Office being the anchor institution.

In mid-2008 the Central Head Office of "Kooperation E-Medien Österreich (KEMÖ)", the Austrian Academic Library Consortium, became an organisational department of the Head Office. The Austrian Academic Library Consortium is engaged in the acquisition and licensing of electronic resources in the frame of consortia and the specific challenges of these media as well as relevant knowledgebuilding and a generator of ideas and innovations for developments in this area. The members of the Austrian Academic Library Consortium and of the Austrian Library Network are not the same, but the overlap is considerable.

\subsection{Network Architecture}

Day-to-day tasks and workflows in the Austrian Library Network are currently spread across a central and several local systems, following the guiding principle "as much centralisation as needed, as much decentralisation as possible". Due to its history and development, the Austrian Library Network is in the lucky situation to have a central catalogue with hardly any duplicates and to be very homogenous in terms of the technical systems used. Except for one case the integrated library systems supplied by Ex Libris - Aleph and Alephino - are used by the Austrian Library Network. Cataloguing is done in the central database. Moreover, all auxiliary tools and features are provided and maintained in the central system in order to avoid any effort for the member libraries at this point. Local library management is done through the corresponding local library systems. Larger libraries have their own systems, whereas smaller libraries are put together in joint Aleph systems made available and managed by the Head Office. Thanks to the mutual automatic synchronisation of data (this is called replication) the various systems nevertheless constitute one organism. Due to data replication enhanced bibliographic information is available to all members in real time and up-to-date library holdings information from the local systems are visible in the central database. The strong and powerful relationship between the central and local systems provides the basis for many services offered within the Austrian Library Network.

The Austrian Library Network substantially benefits from the increased efficiency of this cooperation. This is the reason why the Head Office takes action whenever a sufficiently large group of members shares the same or 
similar interests. By developing and providing consistent services embedded in the overall network for several institutions, services can be offered which could not be rendered by one institution itself as to quality and cost. Hence, the Head Office amongst others always aims at finding and realizing a leverage effect as large as possible. Over the past years numerous traditional workflows have been optimised thanks to this approach.

In 2009 Ex Libris' product Primo was implemented and a central Primo instance was set up as discovery and delivery solution, with the data still coming from the central Aleph system. In addition to that, other products, such as Summon, EDS and vuFind, are in use. Adopting search engine technologies was promoted for strategic reasons, as new cloud-based library management systems no longer include traditional OPACs for end users.

\section{Setting sails for new horizons}

\subsection{Starting point}

Aleph 500 is a very sophisticated system to manage printed material and other traditional media. However, increasingly significant requirements are not supported by the system architecture of Aleph 500. Managing electronic media, especially in a consortia environment, and compiling meaningful statistics is not possible. Solutions are needed for these requirements in view of the often dominating budget share of electronic media and because controlling departments more and more often request respective data. The Aleph 500 system is very stable, but is no longer based on modern technologies. As vendors had already been working intensely on successor systems, it has been necessary since 2009 to engage in scenarios on how to replace Aleph 500.

There were no doubts that the Austrian Library Network with its well-working and efficient environment based on the modes and possibilities of cooperation including the interrelated synergy effects should be preserved. Furthermore, disturbances for librarians should be as minor as possible during the expected transition phase of several years and existing functionalities should be kept up to the highest possible extent.

This consensus was followed by an intense and to some extent controversial opinion-forming process that involved library directors and the boards of the Austrian Library Network as well as experts of the Library Network. Market exploration and preliminary talks with vendors acting in the field of integrated library systems showed a tendency towards cloud-based solutions and a certain concentration process on the European library market with a limited number of eligible providers. Moreover, the pros and cons of open source solutions were discussed in-depth, but ultimately it was decided to give up on this option.

Meanwhile, working on a testing manual was started which stated both the specifications and the tasks to be demonstrated by interested bidders in a real system. To this end and for the later subsequent technical and functional evaluation of the bids the Austrian Library Network bundled the expertise of more than 50 experts of different libraries and the Head Office. By bringing experts of the libraries affected by the system change on board, the catalogues of requirements and system specifications became very thorough and better acceptance of the final solution was achieved. A precondition was that the required functionalities were described instead of specific solutions. This pragmatic approach has been adopted by the Austrian Library Network for many years.

Besides, it was necessary to find the legally correct approach to process the acquisition of the new system. It became clear very soon that an EU-wide tendering procedure has to be conducted. Organisational, technical and functional problems had to be solved in this context.

In terms of organisation it was essential to find a way to implement the tendering procedure "sufficiently strong" (in other words: to have enough institutions committing themselves to a new system) and to be able to provide the result of the tendering procedure to all members of the Austrian Library Network. Neither a tendering procedure covering the Head Office alone nor a tendering procedure which included all members of the Austrian Library Network was conceivable. The Head Office does not have the means to pre-finance such expenditure and due to the lack of any authority to give directives it cannot compel a member of the Austrian Library Network to adopt the system chosen by the Head Office. In line with the longterm and trustful cooperation in the Austrian Library Network a core group made up of 13 member libraries (among them the Austrian National Library and 9 university libraries) and the Head Office jointly realised the tendering procedure as a group of contracting bodies based on internal rules and regulations. An option clause in the subsequent service agreement allows the remaining members of the Austrian Library Network to opt in.

In terms of technical and functional aspects the tender documents had to be as vendor-neutral as possible and a clear evaluation and rating scheme had to be defined. Drawing up the tender documents had the positive side effect that internal processes were analysed and it became clear how desired functionalities had hitherto been determined by necessity or habit. 


\subsection{Selection Process}

The tender was made public EU-wide on October $29^{\text {th }}$, 2013. A two-stage negotiated procedure was chosen in order to be able to handle the complexity of the requirements and the issues to be dealt with appropriately. Experts of Freshfields Bruckhaus Deringer oversaw the very complex tendering procedure in terms of legal aspects.

In general, tenderers were required to demonstrate their systems by processing scenarios to the extent described in the testing manual. Based on the results of the demonstrations and the documents submitted, experts of the participating member libraries and the Head Office did a first assessment of the systems. This assessment determined whether or not the tenderer would remain in or be withdrawn from the following rounds of negotiations.

Current work processes, the indispensable functionalities, the areas where the system would have to be adapted to the libraries' settings if needed to, but also fields, where libraries could adjust their work processes to the conditions of the new systems, had to be scrutinised when the tender documents were drawn up due to the strict procedural rules.

Preliminary market observations had strongly indicated that no integrated library system currently on the market would fulfil all requirements of the contracting parties (especially in terms of the functionalities of the central network system) at the time to the tendering. In order to correctly address this problem, different degrees of fulfilment were defined. So-called "mandatory functional requirements" had to be fulfilled and demonstrated when showing the system. Tenderers had to make "commitment declarations" concerning system properties which had to be realised by the tenderers at the time of the start of operation. Beyond that tenderers had to submit coherent concepts based on general parameters delivered by the contracting parties for so-called "mandatory concept requirements". Mandatory concept requirements were requested among others for the following topics: seamless parallel operation of current and new systems, handling and integration of authority files, consortia electronic resource management and data protection.

Following the demonstration of the system two rounds of negotiations took place in March and July 2015 and Ex Libris submitted its final bid (Ex Libris was the only vendor that took part in the tender). This bid was accepted and Ex Libris was announced the winning tenderer on September $15^{\text {th }}, 2015$.

It has to be pointed out that achieving a positive result in this tendering, which was very complex in many differ- ent aspects, was made possible only by the joint and coordinated acting of all contracting parties.

\subsection{Data and data protection}

Data protection had been of fundamental significance already since the beginning of the whole process as a cloud-based solution was in the offing. The integrated library system is the first real administrative application at universities in Austria to be moved into an external cloud environment and therefore it was necessary to carefully deal with this situation. To this end the contracting parties were looking for external support and conducted a protection requirement analysis in advance as to the existing data in university library systems. The tender documents included strict requirements in terms of data protection. Especially questionable provisions, such as the Safe Harbour Agreement, were considered inadequate and data storage exclusively in Europe was requested.

When data processing is outsourced both the contractual determination of the rights and responsibilities of the service provider including appropriate means of control and the contractual determination of the ownership of the generated data is of crucial relevance. Hence, these parts of the contract were elaborated particularly thoroughly and appropriate reporting obligations were incorporated. However, in spite of all determining and safeguarding a certain basic trust in the future business partner is necessary.

All submitted bids were reviewed and evaluated internally with the help from external experts in terms of data protection, especially with regard to data economy and the possibilities to make personal data anonymous. As the issue of data protection is a very emotional one, discussions followed and requirements were brought up within the contracting parties beyond the library community. As a consequence, it was decided that the requests going beyond the provisions by law which have to be fulfilled according to the contract are to be dealt with and implemented as far as possible in the design phase.

\section{System changeover}

\subsection{Design phase}

Ex Libris and the contracting parties agreed on a first part of the project with a designated duration of six months in the course of which the concepts agreed upon are to be finalised into ready-for-implementation docu- 
ments on the basis of joint communication with Ex Libris. Next to the already mentioned concepts, the design of the acceptance tests to be performed as well as the final versions of the migration plan and the exit plan in case of contract termination are part of this phase. The exit plan must include the concrete mode of handing over data to each contracting party. All technical and functional elaborations and legal clarifications will be available ready for implementation at the end of the design phase.

\subsection{Implementation}

Changing over to the new system will happen in three steps. Six and seven libraries respectively constitute one "cohort" each which changes over to the new system together as a group. The Head Office is the final institution to switch to Alma in the frame of this project. This time table makes sense, as on the one hand the central network functionalities are not yet as advanced as the functionalities for the various libraries and on the other hand a whole range of services provided by the Head Office has to be adjusted and shifted to the new system environment. It has to be mentioned that the data existing in the Austrian Library Network had been analysed already some time ago and independent of the decision on a new integrated library management system. This analysis offers a valuable insight into the use of current systems and allows for the (in part) automatic correction of data errors and standardisation of data structures which will avoid unnecessary problems in the migration.

Following intense preparations the first cohort will switch over to Alma in August 2017. The second cohort will follow at the turn of the year 2017/2018. Finally, the Head Office will start operating the network zone at the end of the first quarter 2018 which also marks the end of the whole process for the contracting parties. As of this time other members of the Austrian Library Network may switch over to Alma.

A special feature of the whole transition phase is that the old systems and Alma will run parallel which makes it possible to maintain existing functions at the central network level to the highest possible extent and to keep disturbances for librarians as minimal as possible. Librarians are supposed to work just in the current system in each case; using other clients is to be avoided. Specific synchronisation mechanism realises the required coupling of the systems to the necessary extent. The bidirectional conversion of the different data formats used - MARC21 in Alma and MAB2 (Automated Library Exchange Format) in
Aleph - is particularly challenging. Running both systems parallel has to be maintained until all members of the Austrian Library Network have switched to Alma. Even with a tight transition plan parallel operation is expected to last several years.

Alma will replace Aleph as the generally used basis for the administration and management of resources and will be the foundation for services built upon this basis.

\section{Concluding Remarks}

\subsection{Expected Pros and Cons of the System Changeover}

The following aspects reflect the perspective of a Head Office can be considered as pros:

- Alma meets the current requirements to a large extent possessing a clear architecture with the result that no workarounds are needed.

- The technology used is up-to-date.

- With its concept of a network zone, which makes it possible to treat affiliated institutions as members of the network already in the system, Alma shows a clearer architecture for network purposes than Aleph.

- Changing over to a new system forces one to analyse work processes and to reflect them in the new environment. This entails opportunities to realise adjustments, standardisations and simplifications which are made use of due to the joint implementation.

- The basic infrastructure and the technical administration of the system are outsourced.

- Data currently stored at the central network level will be maintained at a single global level in the future.

The pros are countered by the following cons:

- Alma involves a loss of control. Data is no longer stored in a local processing environment; accessing the data always depends on the provider. Sufficient contractual arrangements must create certain equilibrium; data downloads and storage at regular intervals on home ground are conceivable.

- Alma is exerting soft pressure to implement uniform work processes, as it no longer offers regional or local specifications (which can also be considered an advantage)

- Alma is not as advanced as current library management systems in use for many years based on clientserver architecture in terms of the management of "classical" processes. Further development in this regard is hoped for. 
- The process of massive concentration in the industry creates oligopolies and leads to an intensified dependence of users on a limited number of vendors.

- Considerable financial resources, resulting e.g. from hosting services, which so far remained in the hands of the Head Office or the surrounding environment, will be redirected to the vendors.

\subsection{Standardisation and Cooperation}

Changing over to the new standard for descriptive cataloguing (RDA) and to the Integrated Authority File (GND) used in the German-speaking countries was finalised before the introduction of Alma which means that there are no further structural adjustments needed in this respect. Switching over to Alma in return, it will on the system level lead to a stronger unification of different system parameters. Aleph had offered many granular possibilities for this purpose which were often used heavily and in many different ways. As a consequence of the joint migration the different configurations within the various cohorts and in the whole Library Network will be analysed and rethought. It will be possible to re-use the model parameterisations drawn up. Joint acting within the Austrian Library Network is a matter of course in this respect as well.

Librarians will not be affected a lot by the lack of a regional data mirror for the GND in the future. The major change will be using the MARC21 format. Direct access to and immediate use of knowledge databases will improve processes.
Whereas at the beginning it is expected that entry controls and test routines to find erroneous entries will deteriorate, the logical data integrity will improve due to the new system architecture. External replication processes will no longer be required in the Alma environment.

Alma will also enable the hitherto unfeasible cooperative administration and management of electronic resources. Joint and utmost efficient processes will be developed in the Austrian Library Network.

Generally speaking, there is no reason to abandon or substantially modify the established and successful methods of creating win-win-situations within the Austrian Library Network. However, the specific techniques will have to change: accessing and editing data will no longer happen on database level, but on a more abstract level via a defined „Application Programming Interface“ (API). In practice, the power and performance of this API will be the crucial factor for automated data manipulation and external integrating additional services.

For this purpose Alma will provide us with an abundance of new possibilities. ${ }^{1}$

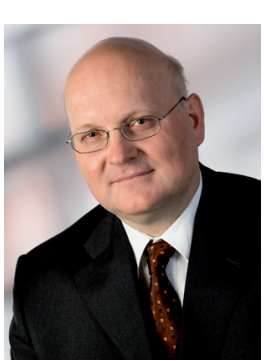

\author{
Wolfgang Hamedinger \\ Managing Director \\ Die Österreichische Bibliothekenverbund \\ und Service Ges.m.b.H. \\ Raimundgasse $1 / 3$ \\ A-1020 Wien \\ Österreich \\ wolfgang.hamedinger@obvsg.at
}

1 The article was translated by Kerstin Stieg. 